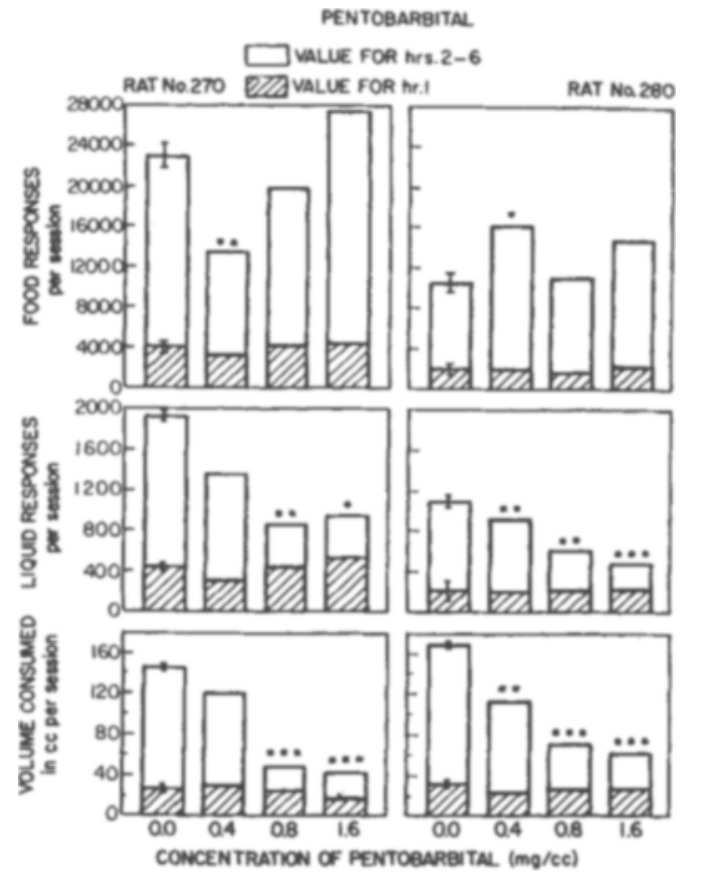

Fig. I. Session totals of food and liquid responses and volume consumed as a function of drug concentration. The standard error of the mean is indicated by the brackets. The striped section at the bottom of each column represents the value for the first hour when water was the drinking liquid. The heights of the bars for the three drug concentrations represent the value for a single 6-h session. ${ }^{*} p<.05,{ }^{* *} p<.01,{ }^{* * *} p<.001$.

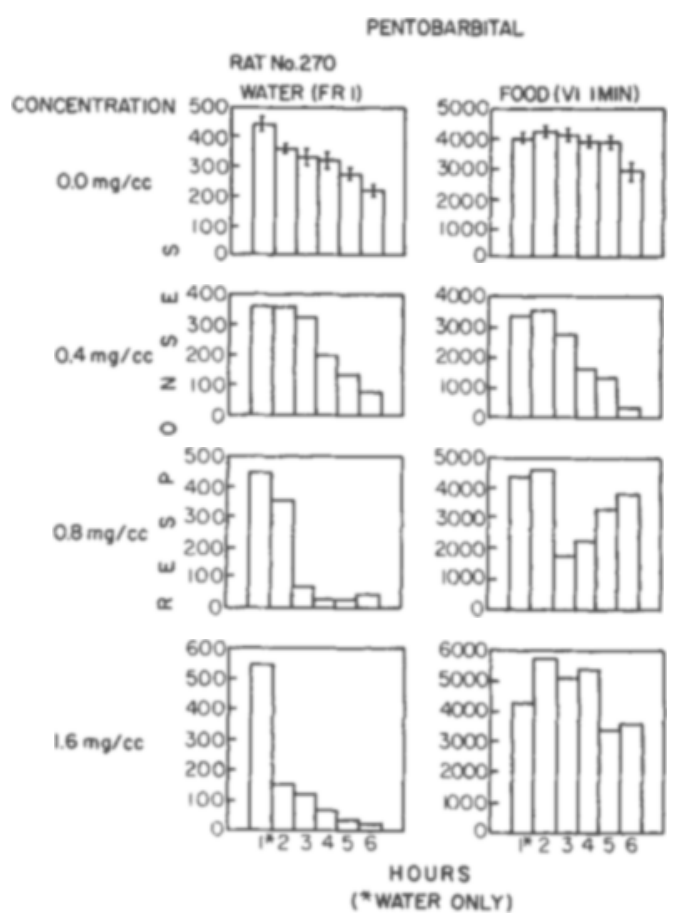

Fig. 2. Time course of responding for liquid and food by Rat 270 as a function of drug concentration. The standard error of the mean is indicated by the brackets at the top of the bars.
The relation between drug concentration and changes in food responses is not simple. This may be partly due to the fact that a "concentration-response curve" is not simply a dose-response curve, but also reflects palatability of the solution.

Schedule-induced polydipsia possesses a number of advantages not found in other procedures for inducing oral drug consump. tion. Low nonaversive dng concentrations may be used, since large liquid volumes are consumed. No liquid deprivation is necessary. Changes in the food baseline can be seen indicating the magnitude and time course of the effect of the self-administered drug. Finally, the liquid consumption is optional in relation to the food reinforced baseline. Removing the liquid does not disrupt the food responding or decrease the number of food reinforcements obtained (Meisch \& Pickens, 1968).

\section{REFERENCES}

CROSSLAND, J., \& LEONARD, B. E. Barbiturate withdrawal convulsions in the rat. Biochemical Pharmacology, supplement, 1963, 12,103.

ESSIG, C. F. Barbiturate withdrawal in white rats. International Journal of Neuropharmacology, 1966, 5, 103-107.

FALK, J. L. Production of polydipsia in normal rats by an intermittent food schedule. Science, $1961,133,195-196$.

LESTER, D. Self-maintenance of intoxication in the rat. Quarterly Joumal of Studies on Alcohol, 1961, 22, 223-231.

MEISCH, R., \& PICKENS, R. Oral self-stimulation of ethanol by the rat. Paper presented at the Psychonomic Society Meeting, St. Louis, Missouri, November, 1968.

SENTER, R. J., \& SINCLAIR, J. D. Selfmaintenance of intoxication in the rat: $A$ modified replication. Psychonomic Science.
$1967,9,291-292$.

NOTES

1. Preparation of this article was supported in part by USPHS Research Grants MH-15349, $\mathrm{MH}-8565$, and $\mathrm{MH}-14112$.

2. Life Insurance Medical Research Fellow.

\title{
The effect of deprivation upon fixed ratio responding'
}

ROBERT W. POWELL, University of
South Florida, Tampa, Fla. 33620

The effect of food deprivation upon fixed-ratio responding was studied in two pigeons. Post reinforcement pausing and response rate were considered separately. Both birds showed significant decreases in pausing as deprivation increased, but response rate did not show a similarly consistent correlation.

In studies of fixed-ratio (FR) behavior, it has become common practice to consider separately the post reinforcement pause and the response rate (Ferster \& Skinner, 1957; Lyon \& Felton, 1966; Powell, 1968). These and other reports have indicated that the post reinforcement pause is susceptible to influence by a number of variables, while the response rate is unaffected by the same variables.

In one of the earliest studies of FR behavior, Sidman \& Stebbins (1954) observed the effects of prefeeding and overfeeding during the session. Their results suggested that the post reinforcement pause 
increases as satiation is approached, but that response rate is relatively constant and independent of the degree of satiation. Malott (1966) has also reported that prefeeding had a much greater effect on response latency than on response rate under FR schedules.

The present investigation was undertaken to analyze the effects of food deprivation upon FR responding. Two aspects of deprivation were studied: (1) the number of hours without food prior to the experimental session; (2) the weight of the animal as a percentage of its free-feeding weight.

\section{METHOD}

The Ss were two adult White Carneaux pigeons, both experimentally naive. They had free access to water and grit in their home cages throughout the experiment.

A Lehigh Valley Pigeon Test Chamber Model $1519 \mathrm{C}$ was employed, programmed by standard relay circuitry. Data were recorded by digital counters and a Gerbrands cumulative recorder. In addition, the post reinforcement pause was measured by recording the pulses ( 4 pps) from a Foringer electronic timer which were initiated by the end of the grain hopper cycle and terminated by the animal's first response. The number of pulses in each pause was recorded by a Grason-Stadler print-out counter.

Mixed grain was used for reinforcement, with grain hopper times of 2.5 and $3.5 \mathrm{sec}$ for Birđs 33 and 44, respectively. Experimental sessions were terminated when 25 reinforcements were obtained.

The birds were trained under gradually extended FR schedules until stable perfor-

Table 1

Pearson Coefficients of Correlation are Presented. They are Calculated on the Relationship Between Hours of Deprivation and Both the Mean Post-Reinforcement Pause and Response Rate in Individual Sessions Under the Two Weight Conditions.

\begin{tabular}{ccccccc}
\hline S & Weight & N & $\begin{array}{c}\text { Post-Reinforcement } \\
\text { Pause }\end{array}$ & $\begin{array}{c}\text { Level of } \\
\text { Significance }\end{array}$ & $\begin{array}{c}\text { Response } \\
\text { Rate }\end{array}$ & $\begin{array}{c}\text { Level of } \\
\text { Significance }\end{array}$ \\
\hline P 33 & $85 \%$ & 50 & -0.384 & .005 & 0.029 & n.s. \\
& $70 \%$ & 50 & -0.232 & .05 & 0.013 & n.s. \\
P 44 & $85 \%$ & 50 & -0.626 & .005 & 0.117 & n.s. \\
& $70 \%$ & 50 & -0.506 & .005 & 0.394 & .005 \\
\hline
\end{tabular}

mance was achieved at FR-50. Stability was identified through inspection of cumulative records. The body weight of the animals was kept within $10 \mathrm{~g}$ of $85 \%$ of their free-feeding weight during baseline training and the first experimental procedure. This consisted of the measurement of the post reinforcement pause and response rate following varied periods of food deprivation. A specific schedule of deprivation periods was not employed. Rather, deprivation periods ranging from 16 to $60 \mathrm{~h}$ were imposed in a random fashion. Supplemental feeding was given following sessions as required to maintain body weight within the designated limits. After 50 sessions at the $85 \%$ weight level, the birds had their body weights reduced to $70 \%$ of free-feeding weight through reduced feeding over 10 days. Their FR performance was then studied for 50 more sessions under varying periods of food deprivation.

\section{RESULTS AND DISCUSSION}

A summary of the data over the entire experiment is presented in Fig. 1. It can be observed that pauses generally decreased as hours of deprivation increased, but that response rate did not show a consistent

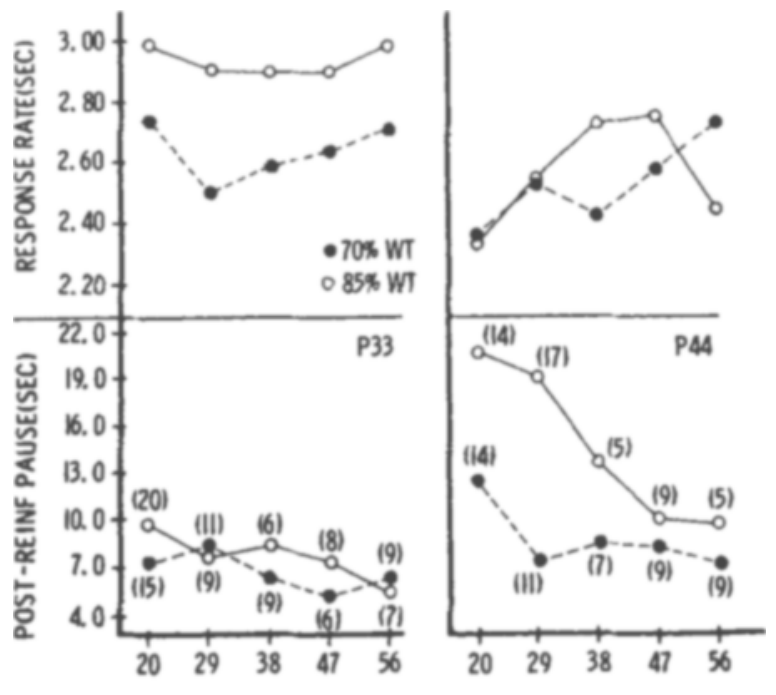

HOURS DEPRIVED

Fig. 1. The mean post reinforcement pause and response rate as a function of hours of deprivation is presented. Hours of deprivation have been divided into five 9 -h class intervals. The median of each class interval appears on the abscissa. The numbers in parentheses indicate the number of sessions upon which the corresponding data points are based. functional relationship with deprivation. Pearson coefficients of correlation based on the above data are presented in Table 1 . This analysis confirms that pausing is more sensitive to deprivation effects than is rate, for although one of the correlations between deprivation and rate is highly significant, all four coefficients based on the pause data are significant, three at the .005 level. The correlations between pausing and deprivation yielded negative values, which is the expected direction.

A comparison of the data for the two animals shows that Bird 44 was generally more sensitive to the effects of deprivation. His correlations were consistently higher for both dependent measures. The difference in performance may relate to the fact that Bird 33 had a higher rate and shorter pauses under the minimal deprivation conditions which were imposed. Thus, his behavior could be influenced to a lesser degree by the effects of deprivation.

The present results lend quantitative support to earlier reports that the postreinforcement pause is more sensitive to drive or deprivation-related variables than is response rate under FR schedules (Sidman \& Stebbins, 1954; Malott, 1966). In this experiment, hours of deprivation was the independent variable, whereas earlier investigations mainly studied the effects of feeding prior to the experimental sessions.

\section{REFERENCES}

FELTON, M., \& LYON, D. O. The postreinforcement pause. Journal of the Experimental Analysis of Behavior, 1966,9, $131-134$.

FERSTER, C. B., \& SKINNER, B. F. Schedules of reinforcement. New York: Appleton-CenturyCrofts, Inc., 1957.

MALOTT, R. W. The effects of prefeeding in plain and chained fixed-ratio schedules of reinforce. ment. Psychonomic Science, 1966, 4, 285-286.

POWELL, R. W. The effect of small sequential changes in fixed-ratio size upon the postreinforcement pause. Journal of the Experimental Analy sis of Behavior, 1968, 11,589-593.

SIDMAN, M., \& STEBBINS, W. C. Satiation effects under fixed-ratio schedules of reinforce. ment. Joumal of Comparative \& Physiological Psychology, 1954, 47, 114-116. NOTE

1. This work was supposted in part by a grant from the University of South Florida Research Council. Reprints may be obtained from the author, Department of Behavioral Science, University of South Florida, Tampa, Florida 33620. 